\title{
Is total endoscopic parathyroidectomy an acceptable treatment for patients with primary hyperparathyroidism due to a presumed solitary adenoma? - comparison of minimally invasive total endoscopic parathyroidectomy and open minimally invasive parathyroidectomy
}

\author{
Yoshiyuki Saito $^{1,2,3}$, Yoshifumi Ikeda ${ }^{3,4}$, Hiroshi Katoh $^{5}$, Atsushi Nakao ${ }^{1,3}$, Hiroshi Takami ${ }^{6}$ \\ ${ }^{1}$ Department of Surgery, International Goodwill Hospital, Yokohama, Kanagawa, Japan; ${ }^{2}$ Department of Surgery, Keio University School of \\ Medicine, Shinjuku-ku, Tokyo, Japan; ${ }^{3}$ Department of Surgery Gastroenterology Center, International University of Health and Welfare, Mita \\ Hospital, Minato-ku, Tokyo, Japan; ${ }^{4}$ Department of Surgery, International University of Health and Welfare, Atami Hospital, Atami, Shizuoka, \\ Japan; ${ }^{5}$ Department of Surgery, Kitasato University School of Medicine, Sagamihara, Kanagawa, Japan; ${ }^{6}$ Department of Surgery, Ito Hospital, \\ Shibuya-ku, Tokyo, Japan \\ Contributions: (I) Conception and design: All authors; (II) Administrative support: Y Ikeda; (III) Provision of study materials or patients: Y Saito, \\ Y Ikeda, A Nakao; (IV) Collection and assembly of data: Y Saito, Y Ikeda; (V) Data analysis and interpretation: Y Saito, Y Ikeda; (VI) Manuscript \\ writing: All authors; (VII) Final approval of manuscript: All authors. \\ Correspondence to: Dr. Yoshiyuki Saito. Department of Surgery, International Goodwill Hospital, 1-28-1 Nishigaoka, Izumi-ku, Yokohama, Kanagawa \\ 245-0006, Japan. Email: yoshiyuksaito@gmail.com.
}

\begin{abstract}
Background: Remote-access thyroidectomy and its cosmetic merit have been widely accepted, but remote-access parathyroidectomy has not become common. There are few reports about the risks and effectiveness of a remote-access endoscopic parathyroidectomy. Herein, we evaluated the risks and benefits of total endoscopic parathyroidectomy (TEP) for patients with primary hyperparathyroidism (PHPT). We retrospectively compared the surgical outcomes of TEP and open minimally invasive parathyroidectomy (MIP).

Methods: We analyzed the cases of 28 patients with PHPT who were scheduled to undergo a MIP at Mita Hospital (Tokyo) during the period from April 2015 to March 2019, all of whom were presumed preoperatively to have a single adenoma.

Results: Eleven of the patients underwent a TEP (10 females, one male; mean age 54.2 years). The other 17 patients underwent an open MIP (11 females, 6 males; mean age 63.5 years). The younger patients and the females tended to select endoscopic surgery as their treatment. The operation time was significantly longer in the TEP group compared to the open MIP group (106 vs. $50 \mathrm{~min}$; $\mathrm{P}<0.001)$. Common postoperative complications (such as recurrent laryngeal nerve paralysis and seroma) did not occur in this series. For the TEP patients who did not undergo a partial thyroidectomy, the mean amount of drainage on the first postoperative day was only $19 \pm 10 \mathrm{~mL}$. The operative cure rate of the minimally invasive parathyroidectomies was $96.4 \%$.
\end{abstract}

Conclusions: TEP is a good surgical procedure for hyperparathyroidism caused by a single adenoma, and it achieves superior cosmetic results without increasing the rate of complications.

Keywords: Total endoscopic parathyroidectomy (TEP); minimally invasive parathyroidectomy (MIP); remote access; primary hyperparathyroidism (PHPT); solitary adenoma

Submitted May 25, 2020. Accepted for publication Sep 30, 2020.

doi: $10.21037 / g s-20-526$

View this article at: http://dx.doi.org/10.21037/gs-20-526 


\section{Introduction}

Approximately $85 \%$ of patients with primary hyperparathyroidism (PHPT) have a single adenoma (1). Over the last few decades, parathyroidectomy with limited exploration, which is called a 'minimally invasive parathyroidectomy (MIP)', replaced conventional bilateral cervical exploration for most patients whose parathyroid tumor can be detected. An MIP is better compared to bilateral cervical exploration in terms of the complication rate, operation time, length of hospital stay, costs, and cosmetic outcome (2,3). A video-assisted parathyroidectomy (VAP) is an endoscopy-assisted surgery that is usually performed with a small central or lateral cervical incision. This method is called a 'minimally invasive video-assisted parathyroidectomy (MIVAP)' (4). A parathyroidectomy without endoscopy through a small skin incision is called an 'open minimally invasive parathyroidectomy (OMIP)' (5-7).

Remote-access thyroidectomy and its cosmetic merits have been widely accepted for some patients (8), but remote-access parathyroidectomy has not become common. A remote-access parathyroidectomy is usually performed with limited exploration. With a central cervical-approach VAP, it is easy to explore the bilateral cervix, whereas by remote-access surgery additional ports are often needed on the contralateral side for an exploration of the bilateral cervix. A remote-access parathyroidectomy without a neck incision is cosmetically superior to VAP.

A remote-access parathyroidectomy can be performed using an endoscopic approach and/or a robotic approach. In Japan, all PHPT patients are eligible for the endoscopic approach when the national health insurance system is used, but the robotic approach is not yet approved under this insurance system. In Japan, an endoscopic axillary, breast, or anterior chest approach is generally used for a total endoscopic parathyroidectomy (TEP), and this comprises a remote-access endoscopic parathyroidectomy.

For the safe and effective performance of a remote-access parathyroidectomy, certain guidelines should be instituted. Few studies have compared the remote-access endoscopic parathyroidectomy with an open parathyroidectomy for performing MIP. We conducted the present study to address whether a remote-access endoscopic parathyroidectomy is effective and safe for PHPT patients whose single parathyroid tumor can be detected, and we compared TEP with OMIP in a retrospective analysis. We present the following article in accordance with the STROBE reporting checklist (available at http://dx.doi.org/10.21037/gs-20-526).

\section{Methods}

\section{Patients}

We analyzed all of the surgical procedures performed from April 2015 to March 2019 for the biochemical diagnosis of PHPT based on the confirmation of a single parathyroid adenoma on imaging at Mita Hospital (Tokyo), of the International University of Health and Welfare. The medical records of these patients were reviewed after approval by the Institutional Ethics Board of Mita Hospital (No. 5-20-06: the registration number of ethics board) and the approach of opt-out consent was used for this retrospective analysis. The study was conducted in accordance with the Declaration of Helsinki (as revised in 2013). During that 4-year period, 37 patients underwent a parathyroidectomy for PHPT at Mita Hospital. We excluded patients if bilateral neck exploration was planned preoperatively for them. Patients who were diagnosed as having more than one adenoma before surgery or who underwent the thoracoscopic approach for an ectopic parathyroid adenoma were also excluded. A final total of 28 patients were enrolled in this study. These patients were scheduled to undergo MIP and were informed of the benefits and disadvantages of both surgical methods (i.e., TEP and OMIP).

\section{Surgical techniques}

TEP was performed as described $(9,10)$. In brief, a 20- to $30-\mathrm{mm}$ incision is made in the axilla (an axillary approach) or the anterior chest (an anterior chest approach). After inflation of the balloon under the platysma muscle, a surgical glove with $5-\mathrm{mm}$ trocars on the first and fifth fingers is fixed to the outer ring of a wound retractor inserted through the skin incision. Carbon dioxide $\left(\mathrm{CO}_{2}\right)$ is insufflated to $6 \mathrm{mmHg}$. An additional $5-\mathrm{mm}$ trocar is inserted near the incision. The anterior border of the sternocleidomastoid muscle is dissected from the sternohyoid muscle. After the parathyroid tumor is identified, it is removed using endoscopic scissors or an ultrasonic scalpel (Figure 1). A partial thyroidectomy was usually performed when the parathyroid tumor was partially embedded in the thyroid or when the parathyroid tumor had irregular margins.

\section{Statistical analyses}

Statistical analyses were conducted using STATA software ver. 15.0 (Stata, College Station, TX). Pearson's chi-squared 



Figure 1 The total endoscopic parathyroidectomy (TEP) procedure. (A) The sternothyroid muscle is severed or split. (B) The parathyroid lesion is identified. (C) The recurrent laryngeal nerve is identified. (D) The parathyroid lesion is removed.

test was used for the comparison of categorical variables. Student's $t$-test and the Mann-Whitney U-test were used to compare continuous variables. For all procedures, a $\mathrm{P}$ value $<0.05$ was considered significant.

\section{Results}

\section{Patient characteristics}

All of the baseline characteristics of the TEP and OMIP groups were similar (Table 1). The TEP group was 10 females and one male, with a mean age of 54.2 years. The OMIP group was 11 females and six males, with a mean age of 63.5 years. The younger patients and the women tended to select endoscopic surgery as their treatment, although there was no significant difference in age or sex distribution between the TEP and OMIP groups. There were no significant differences between the two groups in body mass index (BMI), the largest diameter of the lesion, the preoperative albumin-corrected calcium and intact PTH levels, the rate at which the finding obtained by at least one of three imaging methods (US, CT, or MIBI) was negative, or renal and skeletal comorbidities (which are highly associated with PHPT).

\section{Surgical outcomes}

We next compared the surgical outcomes between the TEP and OMIP groups (Table 2). The operation time was significantly longer in the TEP group compared to the OMIP group [median 106 for interquartile range (IQR) 68-116 min vs. median 50 for IQR 38-71 min; $\mathrm{P}<0.001$ ]. There were no significant differences between the two groups in terms of the amount of bleeding, the use of a partial thyroidectomy together with a parathyroidectomy, the postoperative length of hospital stay, the postoperative intact parathyroid hormone (PTH) level, or the pathological diagnosis. Common postoperative complications (e.g., recurrent laryngeal nerve paralysis and seroma) did not occur in this patient series.

The rate of drainage after parathyroidectomy was significantly higher in the TEP group (100\% vs. $35 \%$; $\mathrm{P}<0.001)$. In the TEP group, all 11 patients had a drain 
Table 1 Baseline characteristics of patients undergoing TEP or OMIP

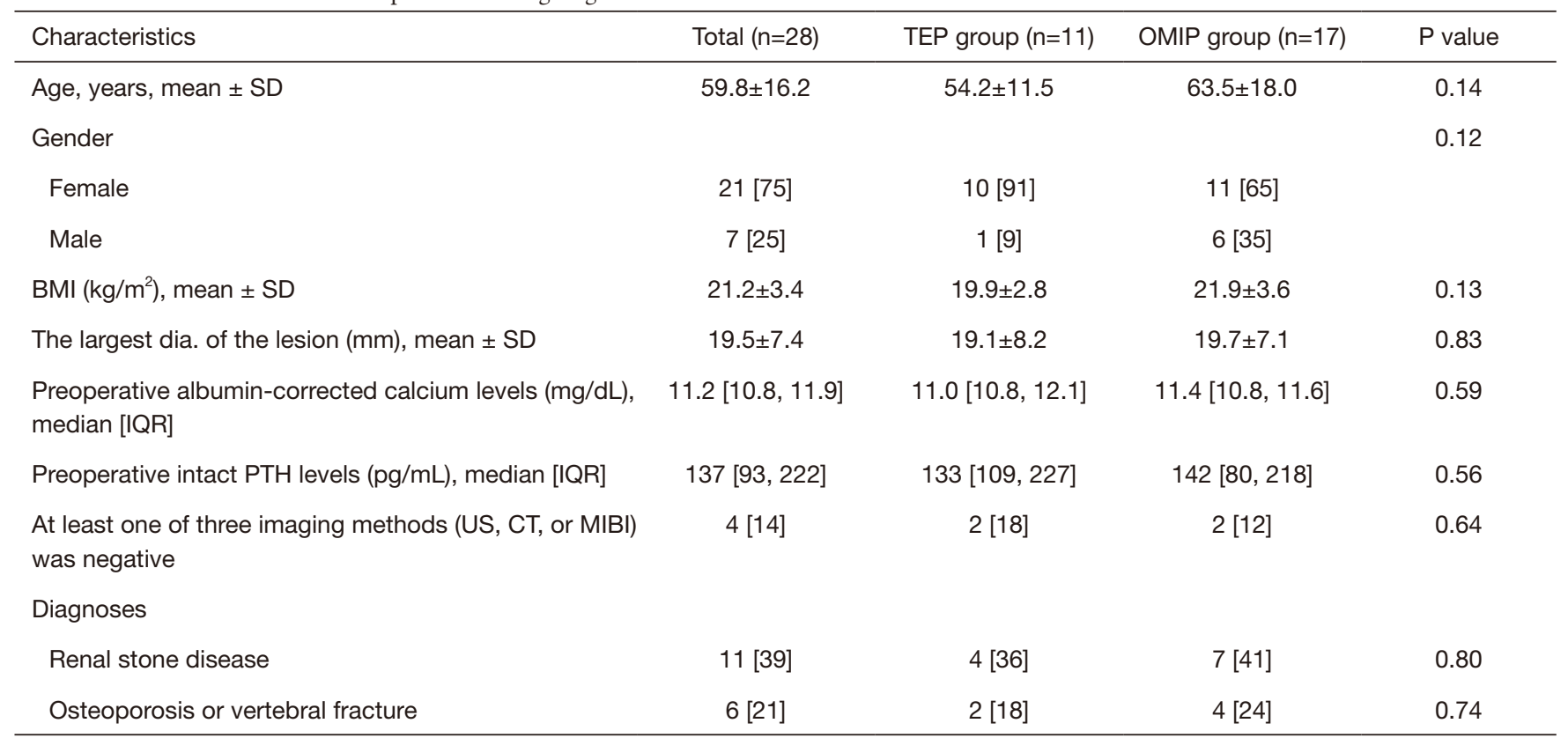

Data are number [\%], mean $\pm \mathrm{SD}$, or median [IQR]. CT, computed tomography; MIBI, methoxyisobutylisonitrile; OMIP, open minimally invasive parathyroidectomy; TEP, total endoscopic parathyroidectomy; US, ultrasound.

Table 2 Comparison of surgical outcomes between the TEP and OMIP groups

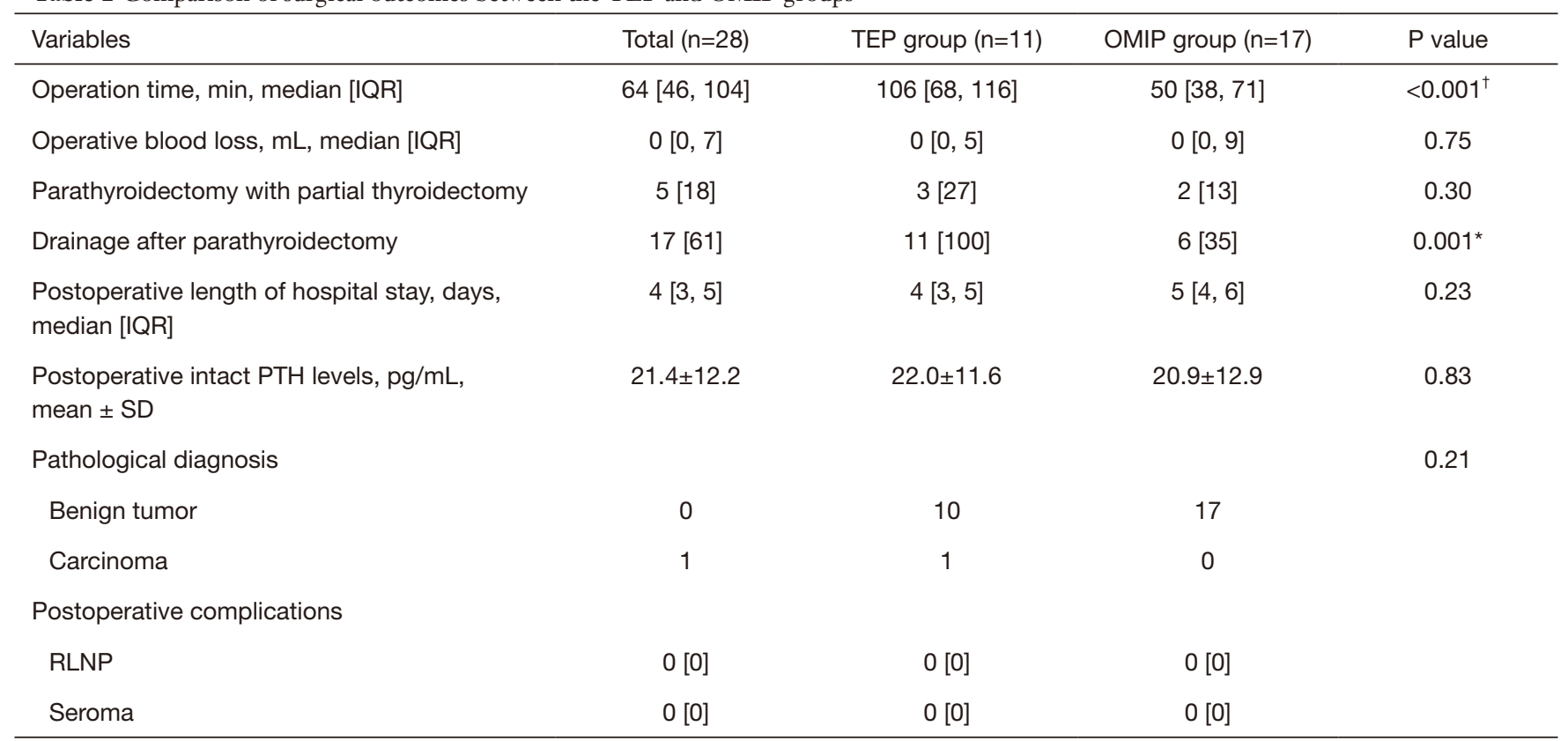

Data are number [\%], mean $\pm \mathrm{SD}$, or median $[\mathrm{IQR}] .{ }^{*}, \mathrm{P}<0.05 .{ }^{\dagger}, \mathrm{P}<0.001$. OMIP, open minimally invasive parathyroidectomy; RLNP, recurrent laryngeal nerve paralysis; TEP, total endoscopic parathyroidectomy. 
placed at the time of the procedure for the prevention of postoperative seroma and the reduction of subcutaneous emphysema. The mean amount of drainage on the first postoperative day for the patients who underwent a TEP without a partial thyroidectomy was $19 \pm 10 \mathrm{~mL}$, compared to $43 \pm 12 \mathrm{~mL}$ for the patients who underwent a TEP with a partial thyroidectomy $(\mathrm{P}=0.009)$.

In this series, the operative cure rate of MIP was $96.4 \%$. All 11 patients in the TEP group were cured with a focused single parathyroidectomy, whereas the intact PTH level of one patient in the OMIP group did not decrease appropriately, and another adenoma was detected on the same side (double adenoma).

\section{Discussion}

TEP was first reported by Gagner et al. in $1996(11,12)$, and at that time a TEP was not remote-access surgery. The initial technique was carried out under constant gas insufflation, using four trocars inserted into the cervical space. This central cervical-approach TEP was capable of bilateral cervical exploration but has not been widely adopted due to its technical difficulty $(12,13)$. This initial approach has therefore been replaced with the two main surgical methods, i.e., VAP with a cervical approach and a remote-access parathyroidectomy. In 2000, our group reported remote-access TEP (9), and that report was thought to be the first case describing a remote-access parathyroidectomy without the presence of a neck scar (14).

An MIP is an excellent surgical technique for patients with a detectable single parathyroid tumor. With the use of intraoperative PTH monitoring and the improvement of the preoperative imaging diagnosis of an abnormal parathyroid gland, the cure rate in PHPT patients who have undergone an MIP has reached $97-99 \%(3,15)$. However, Sugino et $a l$. reported that $4 \%$ of their patients who underwent an MIP had double adenomas (15). In our present series, one patient $(3.6 \%)$ had double adenomas. Therefore, even when the preoperative diagnosis is a single parathyroid adenoma, it is necessary to consider the conversion of an MIP to a unilateral or bilateral cervical exploration.

Because a remote-access TEP is performed in a relatively large subcutaneous space, a TEP provides a better visual field than an OMIP with its small incision. With a TEP, unilateral cervical exploration is possible with a good field of vision and no additional scar. It is also possible to perform the bilateral cervical exploration by the TEP technique, but additional ports on the contralateral side are necessary $(16,17)$.

In the present series, all of the patients who underwent a TEP had a drain placed at the time of the procedure for the prevention of a postoperative seroma and the reduction of the amount of subcutaneous emphysema. The subcutaneous emphysema produced by a TEP usually resolves within postoperative day $1(10,18)$, but subcutaneous emphysema mostly fades away without a drain if the skin flap is pushed backward out of the skin incision (Figure 2).

Seroma is one of the complications associated with remote-access thyroidectomy (19). The formation of a postoperative seroma and the volume of drainage were both greater in a previous study's remote-access thyroidectomy group than in the conventional open thyroidectomy group, and those results were thought to be due to the wider dissection area (including anterior chest wall) used to reach the thyroid gland (20). Regarding the remote-access parathyroidectomy, a few cases of seroma after remoteaccess parathyroidectomy have been reported $(21,22)$, but they were successfully managed conservatively. In our present series, there was no patient who had a seroma after TEP, and the amounts of drainage were small in the patients who underwent a TEP without a partial thyroidectomy. Therefore, making the skin flat in the anterior chest wall might not be directly associated with the development of a postoperative seroma or the volume of drainage. The routine use of a drain did not seem to be necessary for the present TEP cases with limited exploration, because there was very little chance of those complications occurring.

Few studies have compared the remote-access endoscopic parathyroidectomy with the remote-access robotic parathyroidectomy. However, the robotic approach is not yet approved under Japan's national health insurance system, and we can provide only an open or endoscopic parathyroidectomy for PHPT patients in Japan. We thus could not compare TEP with robotic parathyroidectomy in the present study. Tolley et al. compared 15 patients who underwent a remote-access robotic parathyroidectomy to 15 patients who underwent an OMIP, and they reported that the remote-access robotic parathyroidectomy provided superior early cosmesis with equivalent global health improvement (23). In their series, the mean operation time of the robotic parathyroidectomy was $119 \mathrm{~min}$, and no major complications occurred. Our TEP series and their robotic series cannot be simply compared due in part to the different patient backgrounds, but the remote-access 

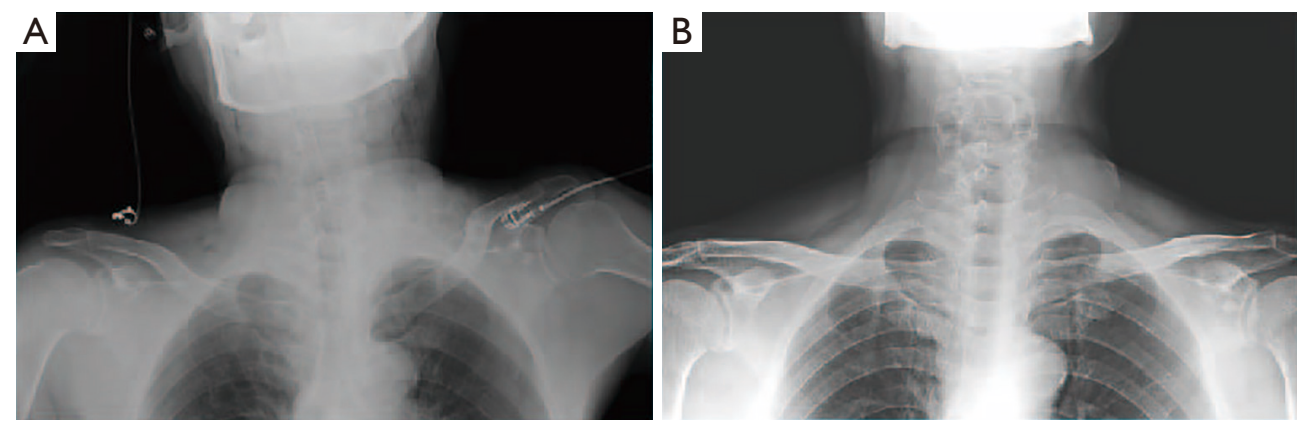

Figure 2 In light of the results of the present analyses, we began to abandon the use of drains in some cases. (A) X-ray before extubation. The subcutaneous emphysema produced by the TEP mostly faded away after the skin flap is pushed backward out of the skin incision. (B) The subcutaneous emphysema resolved in the postoperative period. TEP, total endoscopic parathyroidectomy.

robotic parathyroidectomy and TEP are similar in terms of the operation time and the rate of complications. Regarding the incision, a TEP is usually performed with a $2-$ to $3-\mathrm{cm}$ incision and one additional $5-\mathrm{mm}$ trocar incision, whereas a remote-access robotic parathyroidectomy was reported to be performed with a 4- to 6-cm incision and one or two additional trocar incisions $(23,24)$. Although it is expected that the incision will become shorter with the continued improvement of robotics technology, a TEP appears to provide superior cosmesis at this time.

Despite our encouraging results, there are some limitations to our study. This retrospective analysis may have confounding and selection biases, and the small patient population $(\mathrm{n}=28)$ may have affected our conclusions. Prospective trials of larger numbers of patients are needed to validate our findings.

\section{Conclusions}

The risks and significance of a remote-access endoscopic parathyroidectomy have not been established, but our present analyses demonstrated that a TEP was a good surgical procedure for hyperparathyroidism caused by a single adenoma, and the TEPs that we examined achieved superior cosmetic results and did not increase the rate of complications. Clinicians should consider the choice of TEP carefully for PHPT patients for whom bilateral cervical exploration may be necessary. Focused and unilateral cervical exploration can be performed easily with the TEP technique. More evidence about TEP must be accumulated before clinical guidelines regarding the effective and safe performance of a remote-access parathyroidectomy can be established.

\section{Acknowledgments}

Funding: None.

\section{Footnote}

Reporting Checklist: The authors have completed the STROBE reporting checklist. Available at http://dx.doi. org/10.21037/gs-20-526

Data Sharing Statement: Available at http://dx.doi. org/10.21037/gs-20-526

Conflicts of Interest: All authors have completed the ICMJE uniform disclosure form (available at http://dx.doi. org/10.21037/gs-20-526). The authors have no conflicts of interest to declare.

Ethical Statement: The authors are accountable for all aspects of the work in ensuring that questions related to the accuracy or integrity of any part of the work are appropriately investigated and resolved. The study was conducted in accordance with the Declaration of Helsinki (as revised in 2013). The study was approved by the Institutional Ethics Board of Mita Hospital (Tokyo) (No. 5-20-06: the registration number of ethics board) and the approach of optout consent was used for this retrospective analysis.

Open Access Statement: This is an Open Access article distributed in accordance with the Creative Commons Attribution-NonCommercial-NoDerivs 4.0 International License (CC BY-NC-ND 4.0), which permits the noncommercial replication and distribution of the article with 
the strict proviso that no changes or edits are made and the original work is properly cited (including links to both the formal publication through the relevant DOI and the license). See: https://creativecommons.org/licenses/by-nc-nd/4.0/.

\section{References}

1. Wilhelm SM, Wang TS, Ruan DT, et al. The American Association of Endocrine Surgeons Guidelines for Definitive Management of Primary Hyperparathyroidism. JAMA Surg 2016;151:959-68.

2. Udelsman R. Six hundred fifty-six consecutive explorations for primary hyperparathyroidism. Ann Surg 2002;235:665.

3. Udelsman R, Lin Z, Donovan P. The superiority of minimally invasive parathyroidectomy based on 1650 consecutive patients with primary hyperparathyroidism. Ann Surg 2011;253:585-91.

4. Bellantone R, Raffaelli M, De Crea C, et al. Minimallyinvasive parathyroid surgery. Acta Otorhinolaryngol Ital 2011;31:207.

5. Barczyński M, Cichon S, Konturek A, et al. Minimally invasive video-assisted parathyroidectomy versus open minimally invasive parathyroidectomy for a solitary parathyroid adenoma: A prospective, randomized, blinded trial. World J Surg 2006;30:721-31.

6. Hessman O, Westerdahl J, Al-Suliman N, et al. Randomized clinical trial comparing open with videoassisted minimally invasive parathyroid surgery for primary hyperparathyroidism. Br J Surg 2010;97:177-84.

7. Barczyński M, Papier A, Kenig J, et al. A retrospective case-controlled study of video-assisted versus open minimally invasive parathyroidectomy. Wideochir Inne Tech Maloinwazyjne 2014;9:537-47.

8. Berber E, Bernet V, Fahey TJ 3rd, et al. American Thyroid Association Statement on Remote-Access Thyroid Surgery. Thyroid 2016;26:331-7.

9. Ikeda Y, Takami H. Endoscopic parathyroidectomy. Biomed Pharmacother 2000;54 Suppl 1:52s-56s.

10. Ikeda $Y$, Takami H, Niimi M, et al. Endoscopic thyroidectomy and parathyroidectomy by the axillary approach. Surg Endosc 2002;16:92-5.

11. Gagner M. Endoscopic subtotal parathyroidectomy in patients with primary hyperparathyroidism. Br J Surg 1996;83:875.

12. Brunaud L, Li Z, Van Den Heede K, et al. Endoscopic and robotic parathyroidectomy in patients with primary hyperparathyroidism. Gland Surg 2016;5:352-60.

13. Arora A. An evaluation of emerging technologies in ENT
- Virtual reality simulation \& robotic surgery. 2014. PhD thesis. ISNI: 000000011677 819X.

14. Arora A, Garas G, Tolley N. Robotic parathyroid surgery: Current perspectives and future considerations. ORL J Otorhinolaryngol Relat Spec 2018;80:195-203.

15. Sugino K, Ito K, Nagahama $M$, et al. Minimally invasive surgery for primary hyperparathyroidism with or without intraoperative parathyroid hormone monitoring. Endocr J 2010;57:953-8.

16. Ikeda $Y$, Takami H, Niimi M, et al. Endoscopic total parathyroidectomy by the anterior chest approach for renal hyperparathyroidism. Surg Endosc 2002;16:320-2.

17. Takami H, Ikeda $\mathrm{Y}$, Okinaga $\mathrm{H}$, et al. Recent advances in the management of primary hyperparathyroidism. Endocr J 2003;50:369-77.

18. Ikeda Y, Takami H, Tajima G, et al. Total endoscopic parathyroidectomy. Biomed Pharmacother 2002;56 Suppl $1: 22 \mathrm{~s}-25 \mathrm{~s}$.

19. Kandil EH, Noureldine SI, Yao L, et al. Robotic transaxillary thyroidectomy: An examination of the first one hundred cases. J Am Coll Surg 2012;214:558-64; discussion 564-6.

20. Tae K, Song CM, Ji YB, et al. Oncologic outcomes of robotic thyroidectomy: 5-year experience with propensity score matching. Surg Endosc 2016;30:4785-92.

21. Foley CS, Agcaoglu O, Siperstein AE, et al. Robotic transaxillary endocrine surgery: A comparison with conventional open technique. Surg Endosc 2012;26:2259-66.

22. Karagkounis G, Uzun DD, Mason DP, et al. Robotic surgery for primary hyperparathyroidism. Surg Endosc 2014;28:2702-7.

23. Tolley N, Garas G, Palazzo F, et al. Long-term prospective evaluation comparing robotic parathyroidectomy with minimally invasive open parathyroidectomy for primary hyperparathyroidism. Head Neck 2016;38:E300-6.

24. Mohamed HE, Bhatia P, Aslam R, et al. Robotic transaxillary and retroauricular parathyroid surgery. Gland Surg 2015;4:420.

Cite this article as: Saito Y, Ikeda Y, Katoh H, Nakao A, Takami H. Is total endoscopic parathyroidectomy an acceptable treatment for patients with primary hyperparathyroidism due to a presumed solitary adenoma?-comparison of minimally invasive total endoscopic parathyroidectomy and open minimally invasive parathyroidectomy. Gland Surg 2021;10(1):83-89. doi: 10.21037/gs-20-526 